\title{
Arbor
}

\section{Alimentos para la salud}

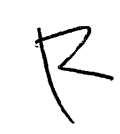

José Bello Gutiérrez

Arbor CLXVIII, 661 (Enero 2001), 1-29 pp.

\section{El binomio Alimento-Salud y sus implicaciones conceptuales}

Uno de los factores que han dejado una huella importante en la sociedad occidental y han caracterizado muchas de sus preocupaciones durante la segunda mitad del siglo XX ha sido el binomio Alimentación-Salud. A lo largo de todos esos años, el ser humano ha desarrollado una gran sensibilidad frente a la posible relación entre la alimentación que recibe y su estado de salud.

Dentro de esta línea, diversos trabajos científicos han puesto de relieve cómo ciertos ingredientes naturales contenidos en los alimentos, proporcionan beneficios medicinales, de tal modo que su presencia en la dieta puede resultar muy útil, unas veces para prevenir y otras para curar algunas enfermedades:

Acciones curativas: 1. oligosacáridos (malas digestiones, altos niveles de colesterol, baja biodisponibilidad de nutrientes). 2. fibra dietética (hipertensión, cáncer de colon).

Acciones preventivas: 1. antioxidantes, betacarotenos, vitamina A y agentes probióticos (cáncer en general) 2. calcio (osteoporosis) 3. proteínas de leguminosas (altos niveles de colesterol, enfermedades cardiovasculares) 4. vitaminas $C$ y $E$ (cataratas, escorbuto, hepatitis) 5. di y poliaminas (demencia senil).

Es evidente que, en la actualidad, nuestra sociedad occidental presenta una gran preocupación por las repercusiones que sobre su salud puedan tener los alimentos que ingiere; incluso se acepta sin reparos, que la salud de una persona o de un grupo de población, es un bien capaz de ser controlado mediante una alimentación adecuada.

Precisamente estos planteamientos han conducido a la aparición en el mercado alimentario de productos que recaban un cierto papel 


\section{José Bello Gutiérrez}

en la medicina nutricional al ofertar beneficios para la salud del consumidor. Sin embargo, muchos de estos productos alimenticios no siempre están de acuerdo con las definiciones admitidas para los atributos alimenticios relacionados con la salud humana.

Considerado desde un punto de vista nutricional, un ALIMENTO es «todo producto que, por sus componentes químicos y por sus características organolépticas, puede formar parte de una dieta con el objeto de calmar el hambre, satisfacer el apetito y aportar los nutrientes necesarios para mantener al organismo en un estado de salud».

Es decir, un alimento es aquel producto, natural o transformado, capaz de suministrar al organismo que lo ingiere la energía y las estructuras químicas necesarias, para que pueda desarrollar sin problemas sus procesos biológicos. Pero un alimento no sólo debe nutrir, sino también ha de poseer tales atributos sensoriales que estimule el apetito y sea apetecible.

En la práctica, existen productos que pueden formar parte de la dieta sin una finalidad nutricional, sólo para satisfacer un deseo apetecido: el café o el té por su acción estimulante; las bebidas carbonatadas, por su acción refrescante; los condimentos y especias, por la función organoléptica que desempeñan; etc.

En relación con los alimentos, cabe hablar hoy día de dos tipos de propiedades: a) nutricionales. b) funcionales.

a) Las Propiedades nutricionales se definen como aquellas que derivan de la capacidad para contribuir al nivel de nutrientes aportados por la dieta alimenticia y que son necesarios para que el organismo pueda llevar a cabo todas las funciones fisiológicas y bioquímicas propias de sus procesos vitales.

De todas las estructuras químicas integradas en la composición de los alimentos, solamente seis pueden realizar la función de nutrientes: agua, proteínas, hidratos de carbono, lípidos, vitaminas y elementos minerales.

b) Se consideran Propiedades funcionales las que, al margen del valor nutritivo, determinan el comportamiento del alimento, entendido éste como un sistema integrado por diversas especies químicas.

Muchas de las estructuras presentes en la composición química de un alimento pueden desempeñar varias funciones determinantes de sus propiedades, al margen de su papel de nutrientes. De hecho, estas propiedades funcionales pueden abarcar tres ámbitos importantes, en relación con el uso y consumo de los alimentos:

- Propiedades sensoriales: son las que hacen apetecible o atractivo a un alimento, en virtud de unos atributos percibidos por los 
órganos de los sentidos: color, sabor, olor, flavor, textura, jugosidad, apariencia, etc.

- Propiedades tecnológicas: son las que permiten contribuir, o al menos facilitar, los procesos vinculados a la tecnología de fabricación industrial, o a las operaciones culinarias, siempre orientados a proporcionar las condiciones más aptas para su consumo.

- Propiedades saludables: son las que contribuyen a que el consumo del alimento no resulte perjudicial desde un punto de vista higiénico-sanitario.

Hoy día se conocen cuáles son las estructuras químicas responsables de las diferentes propiedades específicas de un alimento: las que intervienen en las características organolépticas, como color, sabor, olor, flavor, textura, etc.; las relacionadas con propiedades tecnológicas, esenciales para la específica elaboración de un alimento; incluso las que inciden sobre su calidad higiénico-sanitaria, bien porque proporcionan beneficios saludables o, por el contrario dan lugar a efectos tóxicos. De este modo, cabe relacionar las funciones específicas de cada componente químico con las diferentes propiedades manifestadas por los sistemas alimentarios (Cuadro 1). Todas ellas inciden cada vez más en la demanda de alimentos, porque hoy día se exige que todo producto alimenticio sea nutritivo, apetecible, y sanitariamente correcto.

No obstante, ante el interés por la incidencia de la alimentación sobre la salud, la ciencia de los alimentos se ha encontrado ante la necesidad de adoptar nuevos calificativos, cuya aplicación ofrezca una mejor comprensión de los atributos que, en este sentido, caracterizan a los alimentos comercializados.

- alimento sano: cuando su composición carece de sustancias tóxicas, o de microorganismos patógenos, que puedan ocasionar alguna intoxicación o enfermedad en el que lo consume. Es un requisito que debe cumplir todo alimento en uso, para que desde un punto de vista higiénico-sanitario pueda ser calificado como seguro.

- alimento saludable: cuando carece de sustancias, o al menos no las contiene en cantidades importantes, cuyo frecuente consumo pueda significar algún riesgo de enfermedad crónica.

- alimento para la salud: cuando en su composición participa algún tipo de estructura química, cuya ingestión tenga acreditada actividades preventivas frente a ciertas enfermedades de tipo crónico. 
CUADRO 1. Principales funciones vinculadas a las especies químicas que integran la composición de un alimento

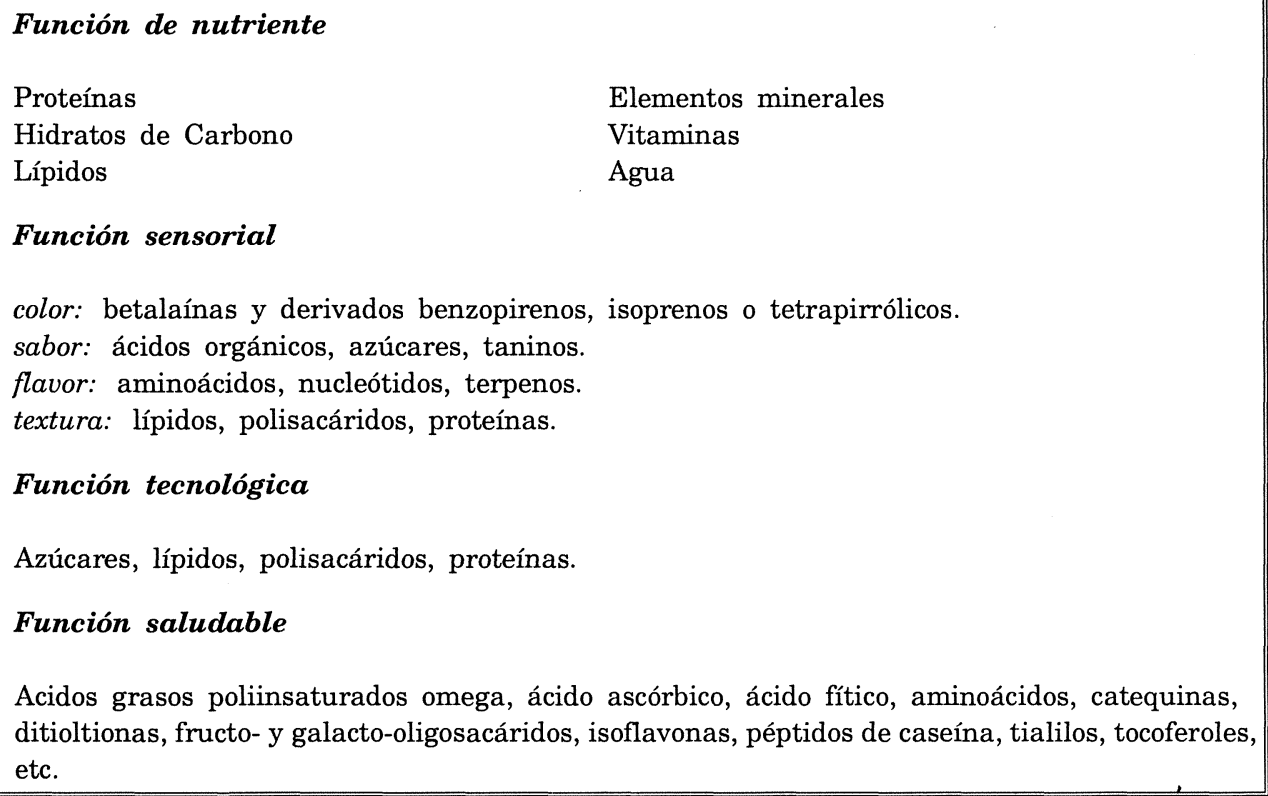

\section{Incidencia en el mercado alimentario}

Aunque las primeras aplicaciones dietéticas de los alimentos se remontan a los tiempos de Hipócrates en el siglo $\mathrm{V}$ antes de Cristo, la evolución que ha experimentado la clínica médica a lo largo del tiempo las ha relegado a consideraciones secundarias. Sin embargo, el interés actual por el binomio Alimentación-Salud hace que, poco a poco, el alimento recupere su papel en la prevención y tratamiento de las enfermedades y alcance una mayor relevancia en el ámbito de la salud humana.

Sin embargo, dentro del amplio espectro de prácticas nutricionales que se aplican como complementarias a los tratamientos clínicos de las enfermedades crónicas existen algunas metodologías que no responden a verdaderos fundamentos científicos: ofertas de suplementos nutricionales, modificaciones dietéticas o sistemas terapéuticos, basados en consideraciones puramente teóricas, sin un fundamento científico que las apoye. Entre otros planteamientos, habría que citar a los numerosos alimentos milagros que en estos últimos tiempos inundan el 


\section{Alimentos para la salud}

mercado alimentario. A pesar de todo, la industria alimentaria ha sabido responder a las demandas de la sociedad en su preocupación por la mejora de su estado de salud y ha puesto en el mercado productos alimenticios avalados por la experimentación científica.

Desde un punto de vista histórico, los primeros en aparecer han sido los alimentos calificados de «Saludables» («Health Foods»). Son productos cuyos diseños resultan adecuados para elaborar dietas que han de ajustarse a requisitos dietéticos estrictos: exentos de gluten, bajos en sodio, pobres en calorías, etc. Entre los primeros comercializados cabe destacar los productos caracterizados por un bajo contenido en sodio, aunque no siempre respondan a las reducidas exigencias de las personas hipertensas. En la práctica, estos alimentos exigen una tecnología de elaboración que plantea problemas prácticos muy difíciles de resolver, sobre todo en cuanto a su aceptación sensorial. Dentro de esta línea, adquieren un gran auge comercial por la década de los años 80 los alimentos que ofertan un aporte de energía inferior a lo tradicional. Suelen llevar en su etiquetado la calificación de «producto light». Pueden citarse diversos tipos que, en sus formulaciones, introducen cambios cuantitativos y cualitativos con el fin de reducir su oferta energética: productos de panadería, bebidas no alcohólicas, caramelos y chicles, derivados lácteos, postres helados, frutas rellenas, salsas mayonesas, sopas, cubiertas, extendedores grasos, etc. No obstante, conviene aclarar que este calificativo puede significar simplemente un aporte de calorías inferior al del alimento convencional. Así por ejemplo, una mermelada se denomina «light» por el simple hecho de contener un $50 \%$ de azúcar, en vez del $60 \%$ habitual; o de un embutido «light», porque su contenido graso resulta ser del $10 \%$ en lugar del $30 \%$; etc.

Posteriormente, aparece una nueva gama comercial de alimentos con la pretensión de ofertar beneficios saludables. Como consecuencia de su contenido en algún tipo de compuesto químico. Estos productos recibieron diversas denominaciones según el país de origen: «Alimentos Funcionales» o «Alimentos para uso saludable específico», en Japón; «Productos Nutracéuticos» o «Alimentos de Diseño» en Estados Unidos; etc.

En su número de marzo de 1997, la Revista Food Technology se planteaba la distinción entre los productos que pueden ser calificados como «Alimentos saludables» y los que deben ser considerados como «Alimentos para la salud». Entiende que con la denominación de «Alimentos saludables» se hace referencia a un concepto algo difuso basado en la ausencia de sustancias con efectos negativos. Por ello, dicha 
denominación también podría ser aplicable a muchos de los alimentos tradicionales cuya ingestión con la dieta no representan peligro para la salud, por los bajos niveles que contienen de esas sustancias consideradas nocivas desde un punto de vista clínico: sal, grasa, azúcar, colesterol, etc. En general, se debe calificar como «saludable» a todo alimento cuya ingestión permita mantener la homeostasis fisiológica del organismo humano que lo consume. Por el contrario, aquellos productos alimenticios que ofrecen algún componente con una actividad positivamente favorable en el ámbito de la prevención de enfermedades crónicas habrían de ser calificados como «Alimentos para la salud».

En la práctica, serán «alimentos saludables» aquellos que carecen, al menos en cantidades importantes, de sustancias que se suponen representan un riesgo para el desarrollo de algún tipo de enfermedad crónica. Deberán ser considerados «alimentos para la salud» aquellos que en su composición contienen sustancias que, una vez consumidas, desarrollan una actividad preventiva frente a ciertas enfermedades. En la actualidad, estos productos están adquiriendo unas perspectivas y unas dimensiones de muchísimo interés, y el mercado alimentario se inunda de ellos, porque el consumidor espera unos beneficios preventivos para su salud.

De acuerdo con la opinión de los especialistas, es posible destacar tres requisitos a cumplir por un producto alimenticio para que pueda ser incluido en el grupo de "Alimentos para la salud»:

a) debe responder a las características propias y genuinas de lo que se entiende por un producto alimenticio: conjunto complejo de sistemas fisicoquímicos, en los que toman parte ingredientes naturales.

b) deben ser consumidos formando parte de un dieta, dentro del modo convencional seguido para cualquier alimento.

c) Su presencia dentro del organismo debe conducir a la regulación de algún proceso biológico concreto: mecanismos de defensa, procesos de envejecimiento, estado físico y/o mental, etc.

De acuerdo con la opinión científica más generalizada, estos nuevos productos alimenticios pueden ser definidos del modo siguiente:

«aquellos alimentos capaces de provocar un impacto positivo sobre la salud de las personas que los consumen, así como sobre su desarrollo físico o sobre su salud mental, al margen de contribuir al aporte dietético de nutrientes».

En definitiva se puede afirmar que algunos componentes químicos de los alimentos pueden desempeñar, además de funciones nutritivas o sensoriales, una tercera función relacionada con los efectos fisiológicos: 
neutralización de sustratos nocivos, prevención de enfermedades, promover la recuperación hasta un estado general de buena salud, etc.; algunos de ellos se indican en el Cuadro 2. Dentro de esta consideración, la legislación alimentaria japonesa establece varios grupos de ingredientes alimenticios con propiedades saludables: 1. Fibra dietética; 2. Oligosacáridos; 3. Polialcoholes; 4. Péptidos y Proteínas; 5. Alcoholes; 6. Isoprenoides y Vitaminas; 7. Colinas; 8. Bacterias ácidolácticas; 9. Elementos minerales; 10. Acidos grasos poliinsaturados; 11. Otros.

CUADRO 2. Principales ingredientes a los que se les atribuye efectos saludables

\begin{tabular}{|c|c|}
\hline Ácidos grasos $\omega-3$ & Prevención enfermedades cardiovasculares. \\
\hline Bacterias acidolácticas & $\begin{array}{l}\text { Regulación de la población microbiana intestinal. } \\
\text { Estímulo del sistema inmunológico. }\end{array}$ \\
\hline Cafeína & Activa la circulación. \\
\hline Fibra dietética & $\begin{array}{l}\text { Rebaja el nivel de colesterol } \\
\text { Previene el cáncer de colon }\end{array}$ \\
\hline Gingseng & Tonificante \\
\hline Minerales (Ca, $\mathrm{Mg}$ ) & Prevención de osteoporosis \\
\hline Oligosacáridos & Reducen el nivel sanguíneo de colesterol \\
\hline Taurina & Recuperación de energía \\
\hline Vitaminas antioxidantes & $\begin{array}{l}\text { Previenen el riesgo de tumores } \\
\text { Modulan el envejecimiento }\end{array}$ \\
\hline
\end{tabular}

\section{Bases científicas de la nueva gama de productos alimenticios}

En opinión de los expertos, muchas de las enfermedades crónicas que de un modo particular afligen a la sociedad occidental, se relacionan de un modo muy estrecho con la dieta alimenticia que se recibe: cáncer, obesidad, hipertensión, trastornos cardiovasculares, etc. Por el contrario, en los últimos años han sido identificadas algunas sustancias naturales presentes en los alimentos, cuyas actividades fisiológicas han resultado tener efectos saludables para el organismo que las ingiere. Según los datos experimentales algunas han destacado por desempeñar un papel primordial tanto en el tratamiento como en la prevención, de diversas enfermedades, en su mayor parte de naturaleza grave: cáncer, diabetes, hipertensión, alteraciones cardiovasculares, osteoporosis, defectos en los tubos neuronales, anormal función del colon, artritis, etc. Tales tipos de sustancias responden a diversos grupos de estructuras químicas. 
Entre las proteínas alimentarias que han reclamado un cierto interés por sus propiedades saludables hay que citar las contenidas en el suero lácteo, normalmente separado en las queserías a partir de las cuajadas caseínicas. En la actualidad, estos concentrados proteicos se incluyen en la alimentación de los deportistas, por su potencial efecto sobre la formación de la masa muscular. También se están describiendo otras consecuencias positivas: estimulación del sistema inmune, reducción de los niveles de LDL-colesterol en sangre y un incremento en la producción de colecistoquinina, implicada en la supresión del apetito.

Algunos de los recientes avances en biomedicina ha permitido conocer cómo proteínas de diversas procedencias (leches, pescados, cereales, legumbres, etc.) pueden ejercer determinadas influencias sobre la fisiología del organismo a través de algunos grupos específicos de aminoácidos, contenidos en sus secuencias primarias, que se liberan por la hidrólisis «in vitro», enzimática o química, dando lugar a péptidos que han demostrado actividades biológicas de extraordinario interés:

a) Actividad opioide: fuentes proteicas como soja, trigo, cebada, maíz y sangre de bovino liberan péptidos con actividad opioide. La función saludable de estos péptidos parece centrarse en todo el tracto intestinal, donde enaltecen la absorción de agua y de electrolitos; de este modo, ejercen un efecto antidiarréico potente. Debido a la actividad mimética de estos péptidos exógenos hacia la morfina, se le ha impuesto el nombre de exorfinas, como oposición al de endorfinas.

b) Actividad inmunomodulante: la digestión con tripsina de algunos tipos de caseínas (alfa s1- y beta), tanto humanas como bovinas, origina péptidos que, en experiencias con ratones, han manifestado cierta capacidad para enaltecer la resistencia frente a la infección ocasionada por algunas bacterias.

c) Actividad transportadora de minerales: varios tipos de caseínas (alfa s1, alfa s2, beta) integran en sus secuencias aminoacídicas algunos residuos fosforilados que corresponden a la serina. En su proteolisis aparecen los denominados caseinofosfopéptidos, capaces de formar complejos solubles con los cationes divalentes aportados por la dieta (calcio, magnesio, hierro, zinc, cobre) y favorecer su solubilidad y absorción.

d) Actividad antihipertensora: las proteolisis enzimáticas de una gran variedad de fuentes (caseína bovina, gelatina, bonito, sardina, atún, zeína del maíz, glutelina y prolamina del arroz, etc.) han proporcionado péptidos que han puesto de manifiesto una cierta actividad antihipertensiva. 
También, los aminoácidos aportados por la alimentación han sido objeto de investigaciones acerca de posibles efectos beneficiosos en el tratamiento de situaciones patológicas: así, bajo condiciones de estrés fisiológico, como puede ser una herida importante, niveles elevados de aminoácidos hidrofílicos de cadena ramificada (leucina, isoleucina, valina) parecen facilitar una mejor cicatrización, aunque el mecanismo implicado en ello no haya podido ser aclarado todavía. La glutamina tiene reconocido un papel importante en el mantenimiento de la integridad del tracto intestinal, tanto en personas sanas, como enfermas: una carencia de glutamina en la dieta puede implicar cambios degenerativos en la mucosa intestinal, con la consiguiente absorción defectuosa de los nutrientes; además, esta circunstancia resulta particularmente peligrosa en el caso de enfermos crónicos, en los que hay que evitar el riesgo de paso de las bacterias entéricas a la sangre.

Los aminoácidos que tienen la capacidad de atravesar la barrera cerebral (aspártico, glutámico, fenilalanina, tirosina y triptófano) pueden influir en la función del sistema nervioso central, al promover la formación de los neurotransmisores: serotonina, dopamina, norepinefrina y epinefrina. Se sabe que los niveles cerebrales de estos aminoácidos se relacionan de modo muy estrecho con el aporte aminoacídico de la dieta, que de este modo puede modular diversos procesos fisiológicos y psicológicos, entre ellos el estado mental y el comportamiento de los individuos.

No obstante, algunas experiencias han demostrado que la ingestión excesiva de algunos aminoácidos durante períodos prolongados, puede significar una amenaza para la salud. De aquí la necesidad de actuar de un modo responsable y con cautela cuando se trate de aconsejar tratamientos con preparados aminoacídicos.

Los conocimientos acerca de los aspectos biológicos de los ácidos grasos insaturados han mejorado gracias a que han sido perfeccionados los métodos analíticos para su identificación y cuantificación y también a los resultados proporcionados por diversos tipos de estudios: epidemiológicos, investigaciones clínicas, experiencias con animales y trabajos con cultivos celulares. Con ello se ha producido un cambio de mentalidad en lo que respecta a las relaciones entre la salud y las enfermedades vinculadas a los ácidos grasos aportados por la dieta. Hace tiempo que se puso de manifiesto cómo la ingestión de ácidos grasos saturados (AGS) tenían la tendencia a elevar los niveles del colesterol sérico. Con posterioridad se observó que su sustitución por ácidos grasos monoinsaturados (AGMI) daba lugar a una reducción de los niveles del LDL-colesterol. En relación con la salud, los ácidos grasos poliinsa- 
turados (AGPI) no sólo deben ser considerados, por sus efectos sobre los niveles de colesterol, sino también por su actividad sobre la agregación plaquetaria y el metabolismo de las prostaglandinas y los leucotrienos, además de otras funciones celulares. En este sentido hay que resaltar de modo especial el papel del ácido alfa-linolénico (AAL), que inicia la serie de los omega-3. En el metabolismo humano se forman los ácidos eicosapentanoico (AEP, 20:5, $\omega-3)$ y docosahexaenoico $(\mathrm{ADH}$, $22: 6, \omega-3)$ a partir del AAL. Hay que señalar como relevante, el papel del $\mathrm{ADH}$ en la formación de los fosfolípidos de las membranas celulares y de los componentes principales de los lípidos complejos del tejido cerebral. Por tanto, cualquier incremento en el consumo dietético de AAL tendrá su importante reflejo en los niveles de $\mathrm{ADH}$ exigidos para cubrir las necesidades humanas. Precisamente, una de las ventajas de las acreditadas dietas de los países mediterráneos es su rica aportación de este ácido graso; son numerosas las propiedades atribuidas a la actividad del ácido AAL:

contribuye al «pool» total de los precursores lipogénicos de la síntesis lipídica cerebral; alivia los síntomas neurológicos clínicos, como parestesia, visión borrosa, entumecimiento; protege frente a los infartos de miocardio; reduce la tensión arterial y rebaja los niveles séricos de triglicéridos y colesterol; potencia los efectos antiarrítmicos y antitrombogénicos; corrige algunos desórdenes inmunológicos; retrasa el desarrollo de tumores; presenta actividad antimalaria y antiparasitaria; es esencial para el óptimo desarrollo neurológico en humanos.

Entre las diferentes estructuras de carbohidratos que forman parte de la composición de los alimentos existen dos grupos a los que se les ha vinculado con alguna propiedad saludable: a) el almidón de arroz, b) los polisacáridos no almidones, que forman la denominada fibra dietética, en sus dos variedades de solubles e insolubles.

a) Almidón de arroz: algunas variedades de arroz se caracterizan por disponer de gránulos de almidón con una digestibilidad bastante lenta en el tracto intestinal y, por tanto, dan lugar después de su ingestión a una respuesta glucémica reducida. Sin duda que la elaboración de productos alimenticios basados en este almidón de arroz, pueden ofrecer la ventaja de proporcionar un bajo índice glucémico, con el correspondiente beneficio tanto para las personas diabéticas como para los atletas. Disponer de productos a base de este tipo de almidón, que se digiere con cierta lentitud, tiene gran importancia para ser ingeridos por los deportistas que necesitan mantener niveles adecuados de glucosa en sangre durante prolongadas etapas de ejercicios 


\section{Alimentos para la salud}

físicos; de este modo, consiguen obtener de modo continuado la energía necesaria para realizar las oxidaciones metabólicas.

b) Fibra dietética: desde un punto de vista bastante general, puede ser definida como «el conjunto de polisacáridos alimentarios que resisten a la acción hidrolítica de los enzimas digestivos propios del tracto gastrointestinal». Desde hace varios años, ha sido objeto de numerosos estudios sobre sus efectos bioquímicos y fisiológicos: incidencia sobre los metabolismos de hidratos de carbono y de lípidos; posible relación con los desórdenes gastrointestinales; papel desarrollado en el cáncer de colon, etc.

Hasta el momento presente, la evidencia científica acumulada ha puesto de relieve que la ingesta de fibra se relaciona, de modo directo, con el normal funcionamiento del tracto digestivo. Más aún, se han obtenido resultados que indican ciertos efectos beneficiosos sobre el constipado intestinal y el síndrome de intestino irritado. No obstante, de acuerdo con los conocimientos disponibles, hay que proceder con cautela y no generalizar sobre la naturaleza preventiva y terapéutica de la fibra. En este sentido, adquiere especial relevancia la necesidad de especificar las fuentes de las fibras alimentarias que se utilizan, porque son las determinantes de su naturaleza química y de sus efectos sobre la salud, es decir, de su funcionalidad.

En un intento de clarificar el concepto de fibra dietética, muchos científicos han optado por definir cada tipo de fibra individual en función de sus propiedades físicas. En este sentido, una característica discriminante empleada ha sido el factor solubilidad, que permite distinguir dos grupos bien definidos: la fibra soluble, capaz de formar soluciones viscosas, y la fibra insoluble. Dos son las fuentes importantes de fibra insoluble: en primer lugar, el salvado de trigo y, después, el salvado de arroz, rico en los dos tipos de fibras. Las fibras solubles son aportadas por muchos productos vegetales, tales como salvado de algunos cereales (arroz, cebada o avena principalmente), verduras y frutas: corresponden a estructuras de polisacáridos capaces de ser ampliamente degradados por las bacterias del colon, dando lugar a toda una serie de sustancias que favorecen el desarrollo de la población microbiana intestinal. Dentro de este tipo de polisacáridos se pueden citar las hemicelulosas del salvado de arroz, las sustancias pécticas de muchas frutas o los betaglucanos del salvado de avena. Todos presentan la particularidad de formar soluciones viscosas, además de tener una gran capacidad de enlazar iones y otros componentes, aunque estas propiedades enlazantes varían según la estructura de la fibra.

En estos últimos años existe una clara insistencia para que la población vuelva a lo que se denomina de modo genérico «dieta me- 
diterránea», caracterizada por un elevado consumo de alimentos de origen vegetal, de modo principal verduras y frutas. Entre otras cosas, muchos de los efectos beneficiosos para la salud de tales alimentos es su contenido en sustancias (algunas de ellas vitaminas), que en el organismo desempeñan funciones antioxidantes: ácido ascórbico, carotenos, flavonoides, isoflavonas, licopeno, luteínas, órgano sulfurados, tocoferoles, tocotrienoles, ubiquinonas, cobre y manganeso.

Algunos de estas fuentes vegetales de antioxidantes han demostrado ser bastante potentes y eficaces. Las funciones saludables de todos estos compuestos están relacionadas con su propiedad fisiológica de contrarrestar los agentes oxidantes biológicos y evitar las posibles alteraciones oxidativas de compuestos, que son esenciales para el funcionamiento normal del organismo humano. Así, vitaminas como el ácido ascórbico, alfa-tocoferol y betacaroteno resultan primordiales para la prevención de tumores por su carácter antioxidante, capaces de neutralizar los nocivos radicales libres que se pueden forman en los tejidos vivos.

Entre los elementos minerales cabe citar la vinculación del Calcio con la osteoporosis y la osteomalacia; el Magnesio con el funcionamiento de los músculos cardíaco y esquelético, la función cerebral y la anorexia; el Hierro con la anemia (carencia) o la oxidación del LDL (exceso); el Zinc con la actividad de las hormonas de crecimiento y tiroideas; el Selenio con el cáncer.

Entre los compuestos no nutrientes hay que citar a las denominadas sustancias fitoquímicas: estructuras químicas presentes en los alimentos vegetales que, una vez ingeridas, resultan muy activas desde el punto de vista fisiológico y medicinal. Entre los alimentos tradicionalmente usados por la medicina popular destacan las cebollas y los ajos, que pertenencen al género Allium, de los que han sido estudiadas, tanto en animales como en humanos, algunas propiedades fisiológicas importantes: actividad fibrinolítica que protege del infarto de miocardio; incidencia sobre los tiempos de coagulación de la sangre; alivio de la hipertensión; reducción de los niveles séricos de triacilgliceroles y del colesterol; estimulación del sistema inmune; bajada de la glucosa en sangre con beneficio para los diabéticos; etc. Se ha sugerido que muchas de estas propiedades se deben a sus contenidos en componentes azufrados, considerándose como los más activos el (prop-2-enil)-propil disulfuro para las cebollas y el di(prop-2-enil) disulfuro en los ajos. También cabe señalar la relevancia del ajo en su contenido en compuestos tioalilos, de fórmula general $\mathrm{H}_{2} \mathrm{C}=\mathrm{CH}-\mathrm{CH}_{2} \mathrm{X}$, en los que $\mathrm{X}$ representa una gran variedad de estructuras orgánicas. 


\section{Alimentos para la salud}

Con respecto a las verduras y otros alimentos vegetales verdes, se ha visto en algunas experiencias con animales, que las clorofilinas, derivadas de las clorofilas, son capaces de reducir la biodisponibilidad de los carcinógenos químicos y también pueden proteger frente a la mutagenicidad de otros carcinógenos, valorada por el test de Ames.

Los lignanos son compuestos difenólicos que se forman en la digestión bacteriana intestinal, a partir de unos precursores aportados por los alimentos de origen vegetal. Se ha señalado que estos lignanos ejercen una cierta influencia sobre la regulación de sustancias estrógenas y presentan actividades antioxidativas y antimitóticas, lo que ha hecho pensar en una posible efecto anticancerígeno, que todavía no ha sido confirmado de un modo experimental.

Una elevada ingestión de plantas crucíferas ha sido asociada con situaciones de bajo riesgo para el desarrollo de tumores malignos. Es posible que la actividad beneficiosa observada se deba a un efecto protector de los isotiocianatos que contienen, aunque no está claro si tales efectos se deben a la propia estructura, muy reactiva por su carbono central fuertemente electrofilico, o bien a sus metabolitos secundarios: carbamatos, tiocarbamatos y derivados de la tiourea. De todos modos, las estructuras activas afectan a la actividad de los enzimas de fase I y II, que metabolizan los xenobióticos y, con ello, modifican la activación oxidativa de los carcinógenos químicos. También las $d i$ tioltionas, unos glucosinolatos presentes en las berzas, parecen tener efectos protectores frente a sustancias químicas de potente actividad cancerígena, como pueden ser las aflatoxinas.

Las saponinas, glicósidos triterpénicos o esteroídicos unidos a mono u oligosacáridos, presentes en una gran variedad de plantas y de modo especial en las leguminosas, sobre todo en garbanzos y soja, han manifestado efectos hipocolesterolemiantes. Tales efectos se han intentado explicar de diversas formas, como impedir la absorción del colesterol o de los ácidos biliares, que al excretarse con las heces, provoca un aumento de la síntesis hepática de dichos ácidos a partir de colesterol con el correspondiente descenso de los niveles sanguíneos.

Los flavonoides son un numeroso grupo de compuestos que incluyen en su esqueleto el conjunto $\mathrm{C}_{6}-\mathrm{C}_{3}-\mathrm{C}_{6}$ y se caracterizan por ser poderosos antioxidantes, muchos de los cuales han presentado una actividad protectora del desarrollo de tumores, que se ha relacionado con una posible inhibición de polimerasas $\mathrm{ARN}$ y $\mathrm{ADN}$ de diversas células, así como a la inactivación de la ornitina descarboxilasa. Claramente se ha visto que los flavonoides, en cuanto compuestos habituales de la dieta, participan en la prevención del cáncer a través de muy diversos mecanismos. 
También uno de ellos, las isoflavonas, tienen una actividad hipocolesterolemiante que se ha vinculado al hecho de poseer una estructura similar a la de los estrógenos, puesto que puede interaccionar con los receptores de éstos, con la consecuencia de un efecto beneficioso sobre los niveles del colesterol sanguíneo.

Otros compuestos fenólicos, tales como las catequinas contenidas en las hojas de té verde y en las uvas, o las curcuminas de la Cúrcuma longa, también han demostrado, en algunas experiencias «in vitro», un efecto inhibidor de la carcinogénesis. Sin embargo, hay que subrayar cómo sustancias que son citostáticas en cultivos de células cancerosas, resultan totalmente ineficaces «in vivo». Por tanto, la obtención de resultados positivos «in vitro» no significa, necesariamente, que también vayan a suceder «in vivo».

Dos componentes de las uvas, el ácido ellagico y el resveratrol, parecen gozar de una actividad quimiopreventiva a través de actuaciones que abarcan a las tres principales etapas de la carcinogénesis: actúan como antioxidante, como antimutágenos e inhiben los enzimas que metabolizan los tóxicos en fase II.

El ácido fítico, un inositol hexafosfato que con frecuencia se encuentra en muchas plantas y sobre todo en cereales, ha presentado diversos efectos beneficiosos: hipocolesterolémico, hipolipidémico y anticarcinogénico, tal vez por su poder antioxidante.

Por último, la población microbiana del tracto intestinal parece tener gran importancia para la salud del organismo que la contiene. Por ello, se justifica el actual intento de incidir sobre la población microbiótica del intestino grueso y sobre su actividad metabólica. En esta línea surgen ofertas de productos alimenticios que proporcionan suplementos alimenticios de microorganismos vivos (agentes probióticos), que mejoran el equilibrio microbiano intestinal. Se han atribuido diversos efectos beneficiosos a la ingestión de agentes probióticos: a) favorece el crecimiento (experimentado en ratas y pollos), b) contribuye a la síntesis de algunas vitaminas en el intestino: tiamina, riboflavina, niacina, cianocobalamina y ácido fólico, d) favorece la absorción intestinal de minerales, e) reduce la población patógena al producir acético, láctico y bacteriocinas, f) mejora de la intolerancia a la lactosa ( $L a c$ tobacillus accidophilus), g) inhibición de sistemas enzimáticos potencialmente nocivos, asociados al cáncer de colon (experiencias con animales), h) alivia el constipado intestinal, i) rebaja los niveles séricos de colesterol, $\mathrm{j}$ ) inhibe la actividad mutagénica de algunas sustancias. A pesar de ser conocidos y usados desde hace muchos años, sin embargo los fundamentos científicos que apoyen sus pretendidos beneficios son 


\section{Alimentos para la salud}

todavía poco concluyentes. Desde luego, ha sido demostrada su eficacia para corregir algunos desórdenes intestinales; incluso, no resulta aventurado pensar que su actividad abarca tanto a la inhibición del crecimiento de los microorganismos patógenos como a la estimulación de la respuesta inmune, aunque los mecanismos responsables de estos efectos necesiten ser bien aclarados. En opinión de algunos especialistas, los alimentos probióticos han sido reducidos a un nivel bastante simplista dentro del ámbito de los productos comercializados.

\section{Principales aplicaciones clínicas de los "Alimentos para la salud»}

Entre los diferentes ámbitos clínicos en los que los «Alimentos para la salud» pueden jugar un papel relevante cabe destacar cinco: 1 . enfermedades cardiovasculares; 2 . desarrollo de tumores malignos; 3 . obesidad; 4. control de la función inmune; 5 . modulación del envejecimiento; 5. comportamiento humano.

\section{Alimentos que reducen el riesgo de enfermedades cardiovasculares:}

Desde hace muchos años, las enfermedades cardiovasculares (ECV) han sido la causa de una elevada mortalidad entre la población humana occidental. Como agentes causales, o al menos indicadores de riesgo, fueron en principio sugeridas las elevadas concentraciones de colesterol en sangre (hipótesis lipídica), y posteriormente la oxidación del colesterol por la acción de radicales libres (hipótesis oxidante). Los estudios bioquímicos y epidemiológicos han hecho sospechar que el posible factor responsable es la ingesta inadecuada de aquellos micronutrientes que, como los tocoferoles, el betacaroteno y el ácido ascórbico, están relacionados con actividades antioxidantes.

En efecto, las sustancias con actividad de vitamina E rompen la cadena de radicales libres provocadoras de peroxidaciones en los ácidos grasos poliinsaturados. Función similar pueden desempeñar el betacaroteno y otros carotenoides, de modo fundamental en los tejidos con una baja presión parcial de oxígeno. También, la vitamina C limpia de radicales libres los compartimentos acuosos de las células, así como puede contribuir a la regeneración de la actividad vitamínica E. En adición, varios enzimas antioxidantes, como la glutation peroxidasa, las catalasas y la superóxido dismutasa metabolizan los compuestos 
intermediarios tóxicos, producidos en las oxidaciones de los materiales biológicos. A menudo, estos enzimas requieren la presencia de micronutrientes para realizar su actividad catalítica: Se, Fe, Cu, Zn, Mn.

Según ha podido observarse, la mortalidad debida a ECV resulta inversamente proporcional al denominado «indice antioxidante acumulativo (I.A.A.)", que se define de acuerdo con la ecuación siguiente:

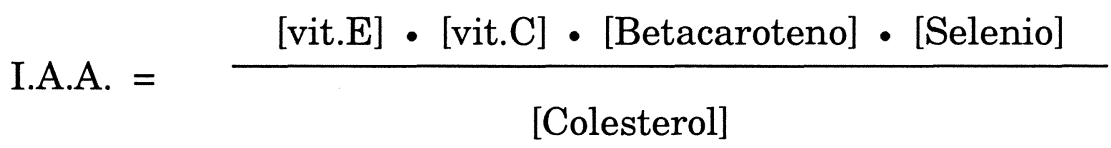

donde las concentraciones corresponden a las valoradas en el plasma sanguíneo.

Se ha comprobado que la incidencia de ECV está fuertemente relacionada con los niveles plasmáticos de vitamina E. Los carotenoides desempeñan una función biológica similar y, de todos ellos, los más eficaces son el betacaroteno y el licopeno, capaces de inhibir la oxidación, hasta su forma aterogénica, de las moléculas de lipoproteínas LDL, vinculadas al transporte sanguíneo del colesterol. También el ácido ascórbico tiene esta propiedad de protección frente a las peroxidaciones de los lípidos de las biomembranas y de las moléculas de LDL, por su eficacia para atrapar los radicales peroxilos en la fase acuosa del citosol, o plasma celular. Un hecho comprobado es la relación inversa entre las incidencia de ECV y las concentraciones en plasma de vitamina C. Incluso, una deficiencia en ascorbato incrementa la concentración en plasma de lipoproteínas(a), importante marcador aterogénico.

Los sistemas relacionados con la antioxidación requieren como cofactores ciertos elementos que se encuentran en los alimentos en cantidades traza: selenio, para la glutation peroxidasa; cobre, zinc y manganeso para la superóxido dismutasa; hierro para la catalasa. Por tanto, una ingestión inadecuada de estos elementos trazas puede comprometer la eficacia de los mecanismos biológicos de la defensa antioxidante. Esta circunstancia puede resultar particularmente relevante para el grupo de personas de la tercera edad.

Aparte de las sustancias citadas, los alimentos pueden contener una cierta variedad de otras sustancias con actividad antioxidante, que igualmente pueden alcanzar una significación nutricional en la prevención de las ECV. Así, la ubiquinona, o coenzima $\mathrm{Q}_{10}$, de estructura similar a las vitaminas $\mathrm{E}$ puede proteger de la peroxidación a los lípidos de las membranas celulares y de las moléculas de LDL, además de contribuir a la regeneración de la vitamina E. Es una molécula 


\section{Alimentos para la salud}

biológica que se sintetiza en el organismo humano a partir de los precursores de la síntesis del colesterol. Como esta capacidad de síntesis se reduce con la edad, quiere decir que su presencia en el organismo de las personas de la tercera edad pasa a depender de lo que se reciba con los alimentos.

También, sustancias polifenoles, tales como los flavonoides, presentan por su semejanza estructural con la vitamina $\mathrm{E}$, cierto interés como antioxidantes capaces de prevenir la formación de radicales libres. En realidad, la importancia dietética de cada tipo de alimento depende de las cantidades consumidas con la dieta. En el cuadro 3 se indican las principales fuentes de estos compuestos antioxidantes.

\section{Alimentos que reducen el riesgo de tumores malignos:}

Se admite que algunos componentes específicos de los alimentos pueden modificar el proceso de desarrollo de tumores cancerosos, unas veces porque alteran la formación de carcinógenos, otras porque modifican su activación metabólica. Sin embargo, a pesar de que se reconozca que algunos nutrientes son capaces de modificar los procesos cancerosos, todavía no están bien definidas sus implicaciones clínicas. Resulta escasa la información acerca del papel desempeñado por los hábitos alimentarios en el fenómeno carcinogénico, aunque existen aportaciones epidemiológicas y experimentales que apoyan estos efectos positivos.

CuAdro 3. Alimentos de origen vegetal considerados como fuentes importantes de sustancias antioxidantes

\begin{tabular}{||l|l|}
\hline Ácido ascórbico: & $\begin{array}{l}\text { calabazas, cítricos, coles de Bruselas, fresas, kiwis, patatas nuevas, } \\
\text { pasas, pimientos verdes. } \\
\text { achicorias, albaricoques, batatas, calabazas, col rizada, espinacas, } \\
\text { melones, pimientos rojos, zanahorias. } \\
\text { aceitunas, calabazas, ciruelas, espárragos, hongos, kiwis, legumbres, } \\
\text { pasas, patatas, plátanos, uvas. }\end{array}$ \\
Cobre: & $\begin{array}{l}\text { ajos, cebollas, puerros. } \\
\text { cacahuetes, cebollas, cítricos, fresas, habas, manzanas, tés, uvas. } \\
\text { órgano-sulfurados: } \\
\text { Flavonoides: } \\
\begin{array}{l}\text { Licopeno: } \\
\text { Manganeso: }\end{array}\end{array}$ \\
$\begin{array}{l}\text { Tocoferoles: } \\
\text { espinacas, legumbres, pasas, piñas, plátanos, remolachas. } \\
\text { brécoles, col rizada, espárragos, espinacas, legumbres, salvado de arroz, } \\
\text { tomates. } \\
\text { ajos, alubias, espinacas, habas. }\end{array}$ \\
Ubiquinonas:
\end{tabular}


Se conocen alimentos que pueden actuar como modificadores de los procesos tumorales a través de diversos tipos de mecanismos:

a) Por destoxificación molecular: Ciertas sustancias presentes en algunos alimentos pueden inhibir el desarrollo de tumores al modificar los procesos de bioactivación; así, el selenio y la vitamina $\mathrm{C}$ pueden inhibir la conversión de un procarcinógeno en carcinógeno activo. Otros, como el benzil isotiocianato y el indol-3-carbinol pueden inducir reacciones de conjugación y acelerar la eliminación de carcinógenos. Son muy diversos los alimentos incluidos en este grupo: pepinos, perejil, zanahorias, melocotones, manzanas, arándanos, ajos, cebollas, brécoles, coliflores, pimientos, aceite esencial de limón.

b) Por oponerse a la proliferación celular. Sustancias con actividad de vitamina A, posiblemente el betacaroteno, pueden inhibir los procesos tumorales al oponerse a la proliferación de los tejidos neoplásicos. Cabe citar en este grupo a los granos de cereales, soja, pescados, zanahorias, pepinos, batatas, frutos cítricos, manzanas.

c) Por una actividad antihormonal. Existen compuestos antiestrogénicos que pueden ser los responsables de la inhibición del crecimiento de los tumores dependientes de hormonas. Tal ocurre con soja, zanahorias, hinojo y anís.

Diversos estudios epidemiológicos han proporcionado cierta evidencia acerca de los efectos positivos sobre la reducción del riesgo a desarrollar tumores malignos por parte de algunas sustancias químicas (Cuadro 4) o de algunos alimentos (Cuadro 5).

\section{Alimentos para el control de la obesidad:}

La obesidad es una enfermedad del mundo occidental que se considera, en la mayoría de las veces, estrechamente relacionada con la ingesta de alimentos. Hasta el momento, los principales esfuerzos en la oferta de alimentos han sido dirigidos hacia los productos que aportan poca energía. Entre ellos merecen citarse los que incluyen en su formulación estructuras alternativas a las grasas, capaces de satisfacer las exigencias organolépticas con una menor densidad energética; tal es el caso del empleo de los poliésteres de la sacarosa (Olestra), con el inconveniente nutricional de reducir la absorción de vitaminas liposolubles, que, solubilizadas en el sustituto graso, son arrastradas con las heces.

En relación con la regulación de la obesidad se pueden señalar factores químicos que inciden sobre la grasa corporal a través de mecanismos que alteran la ingesta energética, el gasto energético o la deposición lipídica en los diversos lugares anatómicos: 


\section{Alimentos para la salud}

Macronutrientes: fibra dietética, contenido en ácidos grasos de la serie $\omega-3$.

Micronutrientes: tiamina, $\mathrm{Zn}$.

No nutrientes: cafeína, capsaicina, fitoestrógenos.

CUADRo 4. Evidencia de estudios epidemiológicos acerca de los efectos positivos de algunas sustancias sobre la reducción del riesgo a desarrollar diversos tipos de cáncer

\begin{tabular}{||l|l|l|l|l|l||}
\hline \multicolumn{1}{|c|}{ Sustancia } & \multicolumn{1}{|c|}{ Tipo de Cáncer } & $\begin{array}{c}\text { Convin- } \\
\text { cente }\end{array}$ & Probable & Posible & $\begin{array}{c}\text { Insufi- } \\
\text { ciente }\end{array}$ \\
\hline Almidón & Colon, recto & & & $*$ & \\
\hline $\begin{array}{l}\text { Polisacáridos } \\
\text { no almidones }\end{array}$ & $\begin{array}{l}\text { Páncreas, colon, recto, estómago, } \\
\text { mama }\end{array}$ & & & $*$ & \\
\hline Carotenoides & $\begin{array}{l}\text { Pulmón, esófago, estómago, colon, } \\
\text { recto, mama, cuello del útero }\end{array}$ & & $*$ & & \\
\hline Vitamina C & $\begin{array}{l}\text { Estómago } \\
\text { Boca, faringe, pulmón, cuello del útero } \\
\text { Laringe, colon, recto, mama, vejiga }\end{array}$ & & $*$ & $*$ & $*$ \\
\hline Vitamina E & $\begin{array}{l}\text { Pulmón, cuello del útero } \\
\text { Colon, recto }\end{array}$ & & & $*$ & $*$ \\
\hline Retinol & Vejiga & & & & $*$ \\
\hline Folatos & Colon, recto & & & $*$ \\
\hline Metionina & Colon, recto & & & $*$ & \\
\hline Selenio & Pulmón & & & \\
\hline
\end{tabular}

CuAdro 5. Evidencia de estudios epidemiológicos acerca de los efectos positivos de algunos alimentos sobre la reducción del riesgo a desarrollar diversos tipos de cáncer

\begin{tabular}{||l|l|l|l|l|l||}
\hline \multicolumn{1}{|c|}{ Sustancia } & \multicolumn{1}{|c|}{ Tipo de Cáncer } & $\begin{array}{c}\text { Convin- } \\
\text { cente }\end{array}$ & Probable & Posible & $\begin{array}{l}\text { Insufi- } \\
\text { ciente }\end{array}$ \\
\hline Ajos & Estómago & & & $*$ & \\
\hline Cereales totales & $\begin{array}{l}\text { Estómago } \\
\text { Colon }\end{array}$ & & & $*$ & $*$ \\
\hline Verduras y frutas & $\begin{array}{l}\text { Boca, faringe, esófago, pulmón, } \\
\text { estómago } \\
\text { Laringe, páncreas, mama, vejiga } \\
\text { Cuello del útero, ovarios, endometrio, } \\
\text { tiroides }\end{array}$ & $*$ & $*$ & $*$ & \\
\hline Pescados & Mama, ovario & & & & $*$ \\
\hline Cebollas & Estómago & & & & $*$ \\
\hline Té verde & Estómago & & & & $*$ \\
\hline Cafés & Colon, recto & & & \\
\hline
\end{tabular}


No obstante, los problemas referentes al desarrollo de la obesidad podrían ser minimizados cuando se consigan identificar cuáles son los factores con ella relacionados.

En la actualidad existe un gran interés por conocer más a fondo el modo de influir en el apetito. Se ha visto que las xantinas (cafeína y teobromina) y las exorfinas (péptidos pequeños con actividad opioide) se presentan como agentes anoréxicos. Las primeras parecen actuar a nivel cortical y las segundas actúan en el intestino, tanto a nivel central como periférico.

Algunos tipos de «Alimentos para la salud» se presentan como interesantes reguladores del peso corporal, pero hay que tener en cuenta que no todas las personas responden de la misma manera a su ingestión, debido a la influencia de la edad, el género, la predisposición genética y la actividad física. En este sentido, se ha ensayado con una hormona hipotalámica que regula la función pituitaria, pero aunque los resultados parezcan ser favorables, sin embargo no son concluyentes. No obstante, se insiste en el tema y en algunos alimentos se ha creído identificar péptidos y análogos de estos compuestos.

\section{Alimentos que permiten controlar la función inmune:}

En los últimos años se maneja la posibilidad de utilizar dietas específicas para promover un estado de inmunidad óptimo en los individuos sanos, o de mantener las defensas inmunes a niveles normales en aquellos pacientes con inmunidad deprimida. mediante la aplicación de dietas específicas. En definitiva, se acude a planteamientos dietéticos bien estudiados para incidir de modo beneficioso en la inmunidad de algunos pacientes. Incluso, se piensa que este modo de actuar puede representar un medio potencial para reducir el riesgo de enfermedades crónicas, generalmente asociadas con el déficit de inmunidad que aparece con la vejez. Una efectiva intervención nutricional puede resultar de interés, no sólo para aplicaciones terapéuticas, sino también para tratamientos profilácticos de sujetos que ofrecen el riesgo de una inmunidad deprimida.

El aminoácido arginina ha sido utilizado en la clínica para el tratamiento de pacientes inmunodeprimidos, y su consumo parece tener un efecto mejorador de los parámetros inmunes durante el estrés fisiológico. También, se ha identificado a la glutamina como una estructura química crítica para mantener a un nivel adecuado el sistema inmune intestinal. También, parece primordial en el desarrollo normal 
de la función inmune celular el aporte dietético de bases purinas y pirimidinas.

El cobre, el hierro, el manganeso, el selenio y el zinc son cinco elementos minerales que en el organismo humano se asocian a sistemas enzimáticos implicados en el sistema inmune, aparte de que puedan actuar como antioxidantes. Aunque se ha podido comprobar que una deficiencia dietética origina desequilibrios en la inmunidad, sin embargo, su consumo como suplemento de la dieta debe ser realizado con cautela por cuanto una ingestión excesiva puede ocasionar efectos tóxicos que, en algunos casos, se traducen en una reducción de las defensas del organismo.

Así mismo, varias vitaminas están implicadas en el correcto mantenimiento de la función inmune, hasta el punto que sus deficiencias en el organismo implican un incremento significativo del riesgo de aparición de situaciones inmunodeficientes. De todas ellas hay que destacar cinco: betacaroteno, calciferol, tocoferol, ácido ascórbico y muchas de las incluidas en el complejo $\mathrm{B}$, aunque no haya sido aclarada la importancia relativa de estas últimas.

\section{Factores dietéticos moduladores del envejecimiento}

Hasta el momento existe muy poca evidencia en lo referente a la capacidad de los factores dietéticos para alterar «per se» el progreso de envejecimiento. Algunos científicos dan por supuesto un solapamiento sustancial entre los factores de riesgo propios del envejecimiento y los implicados en las patologías relacionadas con la edad. No obstante, se admite que cualquier intervención que reduzca los procesos degenerativos deberá hacer más lentos los fenómenos de envejecimiento.

Dentro de esta línea pueden plantearse tres estrategias dietéticas que puedan incidir sobre la velocidad de envejecimiento en los seres humanos: a) reducción de la ingesta calórica; b) prevención y/o reparación del daño oxidativo; c) ingestión de ácidos grasos polinsaturados de la serie $\omega-3$.

Desde luego, son muchos los cambios relacionados con la edad que se hacen reversibles con la restricción calórica, pero resulta muy difícil precisar cuál de ellos es el crítico. De todos los micronutrientes que desempeñan un papel relevante para atenuar el daño oxidativo hay que señalar a la vitamina $\mathrm{C}$ como principal agente, para los compuestos hidrosolubles y la vitamina $\mathrm{E}$ para los liposolubles. Algunas experiencias con animales han permitido relacionar la esperanza de vida con los 
lípidos de la dieta, aunque no ha podido aclararse si el efecto beneficioso se debía a la composición total en ácidos grasos o a la presencia de ácidos de la serie $\omega-3$. Desde luego, estos últimos han demostrado su eficacia frente a enfermedades vinculadas a la edad, como son el cáncer y las enfermedades cardiovasculares. Por su carácter oxidante se discuten los efectos negativos del $\mathrm{Fe}$ y el $\mathrm{Cu}$ de la dieta, en cuanto pueden representar un riesgo para los organismos maduros, pero se desconoce cuál es el nivel de exposición necesario para que se incrementen aquellos cambios degenerativos que aparecen como resultado de la edad.

\section{La relación entre los alimentos de la dieta y el comportamiento humano}

Durante este último cuarto del siglo $\mathrm{XX}$, se ha conseguido reunir un cuerpo sustancial de investigación que pone de relieve la existencia de un cierto impacto de los alimentos ingeridos en el comportamiento y carácter humano. Sin embargo, hay que señalar la dificultad de aplicar esos resultados a la vida real, porque exige una contribución interdisciplinaria y se plantean diversas cuestiones metodológicas en torno a los diseños experimentales.

Entre los componentes de los alimentos que han sido estudiados de un modo especial en relación con su posible incidencia sobre el comportamiento, hay que citar aminoácidos y carbohidratos. En principio, se consideran como más probables aquellos aminoácidos que tienen la capacidad de atravesar la barrera cerebral y son precursores de neurotransmisores cerebrales: triptófano, tirosina y fenilalanina.

El triptófano es precursor de la serotonina y de la hormona melatonina. Desde la década de los años 60 se viene hablando de los efectos sedantes de la administración de este aminoácido neutro. Se ha intentado explicar su posible efecto hipnótico, o sedante, mediante el papel de la serotonina en la regulación del sueño. Existe bastante controversia sobre la naturaleza de sus efectos acerca de los niveles de vigilia y de sueño. En el paso del triptófano a través de la barrera cerebral pueden influir dos factores relacionados con la dieta: la relación de su concentración con el nivel de los demás aminoácidos neutros y la presencia de carbohidratos, que afecta a los niveles plasmáticos de los aminoácidos neutros superiores.

La tirosina es el precursor de tres catecolaminas cerebrales: dopamina, norepinefrina y epinefrina, cuyos excesos de secreción se asocian 


\section{Alimentos para la salud}

con la exposición a un estrés agudo. La administración de tirosina ha manifestado efectos beneficiosos en individuos estresados, a los que mejora su memoria y la recuperación de la fatiga mental. En cambio, la fenilalanina que también es un precursor de catecolaminas cerebrales, no ha presentado, hasta el momento, efectos notables sobre el comportamiento.

Se ha descubierto que las comidas ricas en proteínas, o en carbohidratos, tienen efectos diferentes sobre un neurotransmisor cerebral clave: la serotonina. Este hecho ha suministrado una base racional para que se deba insistir en la importancia de investigar más a fondo los efectos sobre el comportamiento de aquellos alimentos que aportan determinados nutrientes.

En realidad, hasta el momento no se han podido establecer, de modo evidente, los efectos definitivos provocados sobre el carácter y el comportamiento humano por las proteínas y los carbohidratos de la dieta.

\section{Evolución conceptual}

A pesar de la corta historia de esta nueva gama de productos, las denominaciones recibidas han sido bastante profusas y se han prestado a muchas confusiones. Aunque en los últimos años se ha avanzado de modo importante acerca de lo que debe ser entendido como alimento cuyo consumo implica beneficios para la salud, sin embargo aún resulta necesaria una mayor profundización para que se establezcan ideas más exactas sobre su concepto y su uso. Diversos grupos de especialistas trabajan en la actualidad, en este sentido, con el fin de acordar una puesta en común sobre su definición y sus opciones de aplicación.

La comercialización de este tipo de productos arranca del empleo de los suplementos alimenticios, definidos en 1994 por la FDA (Administración de Alimentos y Fármacos) de EEUU como «sustancia incorporada a un alimento para incrementar la ingesta diaria en vitaminas, minerales, aminoácidos, etc., y previsto para ser tomado bajo la forma de píldoras, cápsulas, pastillas o líquido, pero nunca como un alimento convencional o como un único producto alimenticio dentro de una comida». No obstante, en la práctica clínica se han señalado diversos efectos adversos, que han aparecido por el abuso de tales suplementos dietéticos (Cuadro 6). Por otra parte, este tipo de productos alimenticios no responde a lo que actualmente se entiende como Alimentos Funcionales o Productos Nutracéuticos. 
Aunque en la práctica, los productos nutracéuticos y los alimentos funcionales hayan sido ideados para reforzar la ingesta en agentes bioactivos saludables, hoy día se tiende a diferenciar conceptualmente unos de otros.

Así. en Septiembre de 1999, la Revista SCIENCE daba la siguiente definición, sugerida por Zeissel para los Productos Nutracéuticos: «Aquel suplemento dietético que contiene una cantidad concentrada de un agente presumiblemente bioactivo, extraído de una materia alimenticia e incluido dentro de una matriz no alimenticia, que para enaltecer la salud se emplea en dosis superiores a las que se encuentra en los alimentos usados como convencionales.»

CUADRo 6. Efectos adversos de suplementos dietéticos

\begin{tabular}{|c|c|}
\hline Aceite de castor & Diarrea y deshidratación. \\
\hline Ácido ascórbico & Excesiva absorción de hierro que conduce a hemacromatosis. \\
\hline Ácido fólico & $\begin{array}{l}\text { Enmascaramiento de una deficiencia en vitamina } B_{12} \text {, que posiblemente } \\
\text { cause daño en el sistema nervioso. }\end{array}$ \\
\hline $\begin{array}{l}\text { Ácidos grasos } \\
\text { insaturados } \omega^{-3}\end{array}$ & $\begin{array}{l}\text { Incremento de las necesidades de vitamina } \mathrm{E} \text { para contrarrestar } \\
\text { los radicales libres y la oxidación lipídica. }\end{array}$ \\
\hline Algas verdeazul & Perturbaciones gastrointestinales (vómitos y diarreas). \\
\hline Betacaroteno & Tumores malignos. \\
\hline Hierro & $\begin{array}{l}\text { Inhibe la absorción de otros minerales. Hemacromatosis. Mortandad } \\
\text { en niños pequeños. }\end{array}$ \\
\hline
\end{tabular}

En cambio, los Alimentos Funcionales deben ser similares en apariencia a los convencionales y deben ser empleados como parte de la dieta normal. Ofrecen uno, o más, ingredientes activos (que tienen efectos fisiológicos o quizás enaltecen la salud) dentro de una matriz alimenticia, como por ejemplo los cereales para el desayuno, que han sido enriquecidos con altas dosis de ácido fólico.

Es decir, hoy día se aplican notas diferenciadoras de lo que debe ser considerado Producto Nutracéutico de lo que corresponde a un Alimento Funcional. Lo esencial de los primeros radica en su carácter de ingrediente específico, mientras que los segundos son alimentos, semejantes a los convencionales, que contienen cantidades significativas de algún compuesto químico, biológicamente activo, capaz de propor- 
cionar algún beneficio para la salud más allá de lo conseguido con alimentos convencionales, siempre bajo dosis óptimas normales. Desde luego, al carecer de un definición legal, tales productos suelen ser objeto de muchas confusiones y abusos. De hecho, son diversos los alimentos de consumo frecuente que pueden ser considerados como poseedores de alguna actividad saludable potencial (Cuadro 7).

CUADRO 7. Actividad saludable potencial atribuida a grupos de alimentos de frecuente consumo humano

\begin{tabular}{||l|l||}
\hline \multicolumn{1}{|c|}{ Alimento } & \multicolumn{1}{c|}{ Efecto saludable } \\
\hline $\begin{array}{l}\text { Avena } \\
\text { (betaglucanos) }\end{array}$ & $\begin{array}{l}\text { Modificación de los lípidos séricos, atenuación de la glucemia y de } \\
\text { la respuesta insulínica. }\end{array}$ \\
\hline $\begin{array}{l}\text { Cebollas y ajos } \\
\text { (Tioalilos) }\end{array}$ & $\begin{array}{l}\text { Propiedades antimicrobianas, hipolipídica, antitrombótica, } \\
\text { antiinflamatoria, antioxidante y antimutagénica. }\end{array}$ \\
\hline $\begin{array}{l}\text { Cítricos } \\
\text { (ácido ascórbico) }\end{array}$ & Protección frente a la tumerogénesis. \\
\hline $\begin{array}{l}\text { Crucíferas } \\
\text { (isotiocianatos) }\end{array}$ & $\begin{array}{l}\text { Eficaces en el tratamiento de patologías infecciosas. Posible protección } \\
\text { frente al cáncer de colon. }\end{array}$ \\
\hline $\begin{array}{l}\text { Pescados grasos } \\
\text { (ácidos } \omega-3 \text { ) }\end{array}$ & $\begin{array}{l}\text { Prevención de enfermedades cardiovasculares. } \\
\text { Mejora de la función inmune. }\end{array}$ \\
\hline $\begin{array}{l}\text { Salvado de arroz } \\
\text { (fibra soluble) }\end{array}$ & Efecto hipocolesterolémico. \\
\hline $\begin{array}{l}\text { Salvado de trigo } \\
\text { (fibra insoluble) }\end{array}$ & $\begin{array}{l}\text { Regulación de la función intestinal. Alivio del síndrome de colon } \\
\text { irritado, constipación y diverticulosis. Posible prevención de cáncer } \\
\text { de colon y de mama. }\end{array}$ \\
\hline $\begin{array}{l}\text { Uvas tintas } \\
\text { (ácido ellágico y } \\
\text { resveratrol) }\end{array}$ & Protección del riesgo cardiovascular y del cáncer. \\
\hline
\end{tabular}

\section{Planteamientos comerciales}

En el ámbito de los profesionales de la alimentación, los denominados «Alimentos para la salud» han sido muy discutidos al ser considerados bajo dos estimaciones muy diferentes:

a) Unos hablan de ellos como lo último en los avances científicos para proteger con la dieta unas situaciones fisiológicas saludables. 


\section{José Bello Gutiérrez}

b) Otros los califican de artilugio de mercadotecnia, diseñados para exagerar los posibles efectos beneficiosos saludables de algunos de sus ingredientes.

Aunque el tema ha provocado intensos debates en reuniones científicas, sin embargo la evidencia de algunos resultados experimentales abogan bastante en favor de tales alimentos. Cuando menos hay que reconocerles una gran verosimilitud en sus planteamientos.

Es muy posible, que el éxito de su aceptación y demanda, por parte de los consumidores, se deba a dos circunstancias fundamentales:

El consumidor confía, cada vez más, en los efectos saludables de ciertos ingredientes alimenticios y acepta, sin dificultad, que la alimentación pueda ser un factor crítico en el control de su estado de salud.

Cada vez se dispone de una mejor información, tanto clínica como epidemiológica, que apoya la utilidad y eficacia de esos productos.

Son muchas las empresas que, en diversos países del mundo, han invertido en el desarrollo y mercadotecnia de este tipo de alimentos, bajo las más diversas presentaciones: bebidas blandas, cereales para desayuno, bizcochos, confituras, productos lácteos, bebidas con bacterias acidolácticas, etc.

En Europa, la oferta se ha centrado, de modo principal, en alimentos ricos en ingredientes muy concretos: ácidos grasos de estructura omega, betacaroteno, estructuras azufradas presentes en la composición de los ajos, algunos oligosacáridos, etc. En cambio, el mercado norteamericano se ha inclinado por los alimentos ricos en fibra dietética a base de salvado de avena o de arroz.

A medida que la vida de la población occidental ha incrementado el ritmo de vida y lo ha hecho más estresante, resulta más acuciante la necesidad de productos alimenticios que proporcionen a la vez beneficios nutricionales y efectos psicológicos positivos. La calidad de la alimentación en sus aspectos nutritivos y saludables se percibe, en la actualidad, como una cuestión social, e incluso llega a ser considerada algunas veces como un tema de interés público.

Muchos consumidores piensan que mejoran físicamente cuando incluyen en su dieta alimentos saludables. Incluso algunos, de modo particular las personas de la tercera edad, consideran que su consumo les permite reducir el empleo de medicamentos. En estos planteamientos existe el trasfondo del binomio alimentación-salud, que lleva a distinguir si el uso de los «alimentos para la salud» deben proporcionar un efecto preventivo o una acción terapéutica. No obstante, durante años se ha tenido muy claro que, de modo general, el objetivo esencial de estos alimentos no era curar, sino prevenir. 


\section{Alimentos para la salud}

En Japón obtuvieron un gran desarrollo, incluso con una legislación alimentaria propia, debido al apoyo recibido de la Administración Pública interesada en reducir el gasto sanitario, de modo particular en lo que hacía referencia a los grupos de población que integran la tercera edad. El despliegue alcanzado en países como Japón, EEUU, Alemania, Australia, Canadá, etc. ha exigido, y sigue exigiendo, una gran capacidad tanto tecnológica como de investigación, por lo que viene a ser un ámbito casi exclusivo de las grandes industrias alimentarias. Por lo general, suelen aparecer como soluciones de mercados estancados (como los lácteos y las bebidas), pero también se extiende a otros mercados maduros (cárnicos). En la práctica son productos que cumplen en el ámbito empresarial una doble función: abren nuevas oportunidades comerciales y con su oferta saludable cubren las demandas del consumidor actual.

En España, esta nueva gama de productos alimenticios ha despuntado en el mercado de los lácteos, que ha diversificado sus productos comerciales hacia los alimentos enriquecidos, cuyo consumo habitual pretende ofrecer mejoras saludables. A este sector le sigue el de bebidas con su oferta de productos energéticos, que pretenden devolver al organismo la energía perdida, ayudarle a eliminar las toxinas acumuladas y mejorar el estado de ánimo. Incluso, cabe citar nuevos productos en el sector confitero, que incorporan ingredientes saludables con el fin de llegar a los consumidores adultos. En la práctica, nuestro país dispone actualmente de una oferta variada en esta gama de nuevos productos, entre los que cabe destacar los siguientes.

leches desnatadas ( o semidescremadas) ricas en calcio.

leches enriquecidas en vitamina $\mathrm{D}$.

yogures que contienen agentes probióticos.

embutidos crudos-curados, enriquecidos con bifidobacterias.

huevos ricos en ácidos grasos insaturados $\omega^{-3}$.

huevos ricos en vitamina $\mathrm{E}$.

pastas de hígado y salchichas de ave, ricas en ácidos grasos insaturados $\omega-3$. pastas alimenticias enriquecidas con ácidos grasos insaturados $\omega-3$. cereales para el desayuno ricos en minerales, vitaminas y fibra dietética. mermeladas enriquecidas con fibra dietética, vitaminas y minerales. bebidas energéticas que llevan cafeína, taurina y glucoronolactona.

Tanto el buen uso, como la consideración correcta, de estos nuevos alimentos implica tener en cuenta una serie de factores:

Desde el punto de vista de la medicina nutricional, un alimento es algo más que una suma de nutrientes. 
Un alimento no puede ser considerado como el factor único que influye en el estado de salud, o de bienestar, de una persona; tampoco resulta un factor exclusivo para la resistencia a las enfermedades.

Es muy difícil de establecer, al menos por ahora, el nivel de ingestión considerado óptimo para sustancias con beneficios saludables.

Ningún organismo de expertos ha recomendado el uso rutinario de suplementos alimenticios, cuyas eficacias varían en función de su calidad y de su biodisponibilidad digestiva.

Se conoce la existencia de casos en los que la ingestión de suplementos de nutrientes únicos ha provocado efectos nocivos para la salud.

En resumen, la demanda de «Alimentos para la salud» se basa en dos factores primordiales:

la prevención de algunas enfermedades crónicas,

el incremento de la calidad de vida al favorecer el estado de bienestar del individuo.

Se espera que en los próximos años continúe el incremento de este interés como consecuencia de los resultados científicos que se van obteniendo y que avalan las diferentes propiedades saludables de ciertos ingredientes y alimentos.

\section{Bibliografía}

Bello, J. Los alimentos funcionales o nutracéuticos. I. Nueva gama de productos en la industria alimentaria. Madrid. Alimentaria. Septiembre. pág. 25-30, 1995.

Bello, J. Los alimentos funcionales nutracéuticos. 2. Funciones saludables de algunos componentes de los alimentos. Madrid. Alimentaria. Noviembre. pág. 49-57, 1995.

Bello, J. Principales ámbitos clínicos de aplicación de los alimentos funcionales o nutracéuticos. Madrid. Alimentación, Equipos y Tecnología. Junio. pág 43-48, 1997.

CHILDS, N.M. Nutraceutical Industry Trends. New York: Journal of Nutraceuticals, Functional \& Medical Foods, vol. 2(1). pág. 73-85, 1999.

Firshein, R. The Nutraceutical Revolution. New York: Riverhead Books, Penguin Putnam Inc., 1998.

Goldberg, I. (ed.). Functional Foods. New York and London: Chapman \& Hall, 1994.

Han, C., Tian, J. and Chen, J. The Screening of Anticarcinogenic Ingredientes in TeaPolyphenols. Ney York: Journal of Nutraceuticals, Functional \& Medical Foods, vol. 1(2), pág. 7-24, 1997.

Mazza, G. (ed.). Functional Foods. Biochemical \& Processing Aspects. Lancaster (Pensilvania): Technomic Publishing Company, Inc., 1998.

Murthy, R. and Murthy, M. Omega-3 Fatty Acids as Anti-Inflammatory Agents: A Classical Group of nutraceuticals. New York: Journal of Nutraceuticals, Functional \& Medical Foods, vol 2(1), pág. 53-72, 1999. 


\section{Alimentos para la salud}

Sadler, M.J and Saltmarsh, M. (eds.) Functional Foods. The Consumer, the Produts and the Evidence. Cambridge: The Royal Society of Chemistry, 1998.

Slavin, J.L. Health Benefits of Oligosaccharides. New York: Journal of Nutraceuticals, Functional \& Medical Foods, vol. 1(4), pág. 43-55, 1999.

W.C.R.F. Diet and Health. Recommendations for the Prevention of Cancer. London: World Cancer Research Fund. 1998. 